\title{
Relationship between Digit Finger Ratio and Selected Psychological Vaeiables of Volleyball Players
}

\author{
Nishant Singh ${ }^{1}$ Dr. Minakshi Pathak ${ }^{2}$ \\ ${ }^{1}$ Research Scholar, Sri Satya Sai University of Technology and Medical Science, Sehore \\ ${ }^{2}$ Dean Physical Education, Sri Satya Sai University of Technology and Medical Science, Sehore.
}

\begin{abstract}
The purpose of the study was to find relationship between digit finger ratio and selected psychological variables of Volleyball players. By applying simple random sampling a total number of 100 Volleyball players age ranging between (18-25) selected from Varanasi and nearby to act as a subject for the study. Keeping in mind about specific purpose of the study, the following variables has been selected: Digit finger ratio (Independent variables) Measured by using Vernier calliper (Fink et all, 2006) accurate to0.01mm. And by taken photo copy of right hand palm. Psychological variables (Dependent variables) Aggression constructed by Prof. Anand kr. Shrivastava and Prem Shankar shukla, and Achievement Motivation constructed by Dr. M.L. Kamlesh. In this study correlation design was used for achieving the objectives of the study. In the light of the findings of the present study, the hypothesis that there shall not be any significant impact of digit finger ratio on the psychological variables of Volleyball players was accepted in case of Achievement Motivation, whereas not accepted in the case of Aggression. The level of significance was set at $5 \%$.
\end{abstract}

Keyword: Digit finger Ratio, Aggression, Achievement motivation, Volleyball players.

\section{Introduction}

Elite sporting performance results from the combination of innumerable factors, which interact with one another in a poorly understood but complex manner to mould a talented athlete into a champion (Tucker \& Collins, 2012).

The Digit ratio is the ratio of the lengths of different digits or fingers typically measured from the midpoint of bottom crease where the finger joins the hand to the tip of the finger (Mayhew, Gillam, McDonald \& Ebling, 2007). ). It has been suggested by some scientists that the ratio of two digits in particular, the 2nd (index finger) and 4th (ring finger), is affected by exposure to androgens e.g. testosterone while in the uterus and that this 2D:4D ratio can be considered a crude measure for prenatal androgen exposure, with lower 2D:4D ratios pointing to higher androgen exposure. Digit ratio has been shown to correlate with several psychological traits.

Women with smaller digit ratios report higher, more masculinised scores on the Bam Sex Role Inventory (Csatho et al., 2003a). Men with smaller 2D:4D ratios are perceived as being more masculine and dominant by female observers (Neave et al., 2003).

\section{Procedure}

In this study the selection of subjects, Criterion Measures, collection of data and design.

\section{Selection Of Subjects}

By applying simple random sampling a total number of 100 Volleyball players age ranging between (18-25) selected from Varanasi and nearby to act as a subject for the study.

\section{Selection Of Variables}

Keeping in mind about specific purpose of the study, the following variables has been selected:

1-Digit finger ratio (Independent variables)

2-psychological variables (Dependent variables)

-Aggression

-Achievement Motivation

\section{Criterion Measures}

The criterion measures adopted for the study was as follows:

- Aggression constructed by Prof. Anand kr. Srivastava and Prem Shankar shukla.

- Achievement Motivation constructed by Dr. M.L. Kamlesh

- Digit finger ratio, Measured by using Verniar calliper (Fink et all, 2006) accurate to0.01mm. And by taken photo copy of right hand palm. 


\section{Collection Of Data}

The data were collected at different clubs and stadiums of Varanasi and nearby. Necessary instructions were given to the subjects before administration of the questionnaire.

\section{Design Of The Study}

The Correlation design was used for the study.

\section{Administration Of Questionnaire}

Respondents were called to a common place when they were not busy and have enough time to spare for testing. Necessary instructions were passed on to the subjects before the administration of each test. No time limit for filling in the questionnaire was set, but the subjects were made to respond as quickly as possible once the instructions were clearly understood by them.

\section{Statistical Analysis}

In this study correlation, was used for achieving the objectives of the study. The level of significance was set at $5 \%$.

Table .1: Descriptive Statistics of Selected Psychological Variables and Digit Finger Ratio of Volleyball players

\begin{tabular}{|l|l|l|l|}
\hline Descriptive Statistics & Agg. & Achiev. & Ratio \\
\hline Mean & 16.14 & 25.78 & .8717 \\
\hline Standard Error & .378 & .226 & .00808 \\
\hline Standard Deviation & 3.782 & 2.263 & .08078 \\
\hline Sample Variance & 14.303 & 5.123 & .007 \\
\hline Skewness & -.206 & -.324 & .056 \\
\hline Standard Error of Skewness & .241 & .241 & .241 \\
\hline Kurtosis & -1.282 & -1.078 & .524 \\
\hline Standard Error of Kurtosis & .478 & .478 & .478 \\
\hline Range & 12 & 7 & .41 \\
\hline Minimum & 10 & 22 & .68 \\
\hline Maximum & 22 & 29 & 1.09 \\
\hline
\end{tabular}

Note: Agg= Aggression, Achiev= Achievement Motivation, Ratio= Digit Finger Ratio.

Table-1 revealed that the mean ( \pm standard deviation) of male Volleyball players in relation to Aggression, Achievement Motivation, and Digit Finger Ratio were $16.14( \pm 3.78), 25.78( \pm 2.26)$, and 0.87 $( \pm 0.08)$ respectively.The table also showed other descriptive statistics i.e. standard error and sample variance along with the range showing minimum and maximum score of the subjects. The value of kurtosis and skewness along with the standard error of kurtosis and standard error of skewness itself indicates the normality (scientific authenticity) of the data.

Table.2: Correlation between Digit Finger Ratio and Selected Psychological Variables of Volleyball Player

\begin{tabular}{|l|l|l|}
\hline Selected Psychological Variables & Correlation Coefficient & Sig. \\
\hline Aggression & $.289^{* * *}$ & .004 \\
\hline Achievement Motivation & -.013 & .895 \\
\hline
\end{tabular}

$* * \mathrm{p}<.01 \& * \mathrm{p}<.05$

Table-2 revealed that significant positive relationship was found between Digit Finger Ratio and Aggression $(r=.289, \mathrm{p}<.05)$ In case of Achievement Motivation $(\mathrm{r}=-.013, \mathrm{p}>.05)$ an insignificant relationship was found as the value of coefficient of correlation was insignificant at 0.05 level

\section{Discussion Of Finding}

In the light of the findings of the present study, the hypothesis that there shall not be any significant impact of digit finger ratio on the psychological variables of Volleyball players was accepted in case of Achievement Motivation whereas not accepted in the case of Aggression.

\section{Conclusions}

Following conclusions may be drawn from the obtained result:

* A significant positive relationship was found between Digit Finger Ratio and Aggression of Volleyball players.

* An insignificant relationship was found in case of digit finger ratio and achievement motivation. Of Volleyball players. 


\section{Reference}

[1]. Archer, J., Birring, S.S., Wu, F.C.W., 1998. The association between testosterone and aggression among young men: empiricalfindings and a meta-analysis. Aggressive Behavior 24 (6), 411-420.

[2]. Dockstader, J. B. (1979). Locus of Control and Achievement Motivation Under Condition of Success and Failure in High School Athletes. Dissertation Abstracts International, 39(9), 5407.

[3]. Voracek, M., Reimer, B. \& Dressler, S. G. (2010). Digit ratio (2D:4D) predicts sporting success among female fencers independent from physical, experience, and personality factors. Scandinavian Journal of Medicine \& Science in Sports, 20(6), 853-60. doi: 10.1111/j.1600-0838.2009.01031.x.

[4]. Buck, J.J., Williams, R.M., Hughes, I.A., Acerini, C.L., 2003. Inutero androgen exposure and 2nd to 4th digit length ratiocomparisons between healthy controls and females with classical congenital adrenal hyperplasia. Human Reproduction 18 (5), $976-$ 979.

[5]. Book, A.S., Starzyk, K.B., Quinsey, V.L., 2001. The relationship between testosterone and aggression: a metaanalysis. Aggression and Violent Behavior 6 (6), 579-599.

[6]. Austin, E.J., Manning, J.T., McInroy, K., Mathews, E., 2002. A preliminary investigation of the associations between pers onality, cognitive ability and digit ratio. Personality and Individual Differences 33, 1115-1124.

[7]. Bailey AA, Hurd PL. 2005. Finger length ratio (2D:4D) correlates with physical aggression in men but not in women. Biol Psychol 68:215-222.

[8]. Armstrong CA, Oldham JA. 1999. A comparison of dominant and non-dominant hand strengths. J Hand Surg [Br] 24:421-425. 